\title{
Obesity and Type 2 Diabetes: Two Diseases with a Need for Combined Treatment Strategies - EASO Can Lead the Way
}

\author{
Deborah R. Leitner ${ }^{a} \quad$ Gema Frühbeck $^{b}$ Volkan Yumuk $^{c} \quad$ Karin Schindler $^{d}$ \\ Dragan Micic $^{e}$ Euan Woodward ${ }^{f}$ Hermann Toplak ${ }^{a}$ \\ a Department of Medicine, Medical University Graz, Graz, Austria; ${ }^{b}$ Department of \\ Endocrinology and Nutrition, Clínica Univ. de Navarra, University of Navarra, CIBERobn, \\ Instituto de Salud Carlos III, Pamplona, Spain; ' ${ }^{C}$ Division of Endocrinology, Metabolism \\ and Diabetes, Istanbul University Cerrahpasa Medical Faculty, Istanbul, Turkey; ${ }^{d}$ Division \\ of Endocrinology and Metabolism, Medical University Vienna, Vienna, Austria; ${ }^{\text {Medical }}$

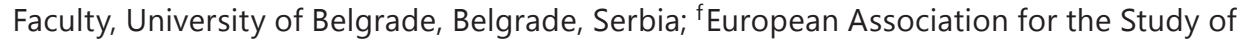 \\ Obesity, London, UK
}

\section{Keywords \\ Obesity · Diabetes · Diabesity}

\begin{abstract}
Obesity is a chronic metabolic disease affecting adults and children worldwide. It has become one of the leading causes of death, as obesity is known to be the main risk factor for a number of non-communicable diseases, in particular type 2 diabetes. This close relationship led to the connotation 'diabesity', highlighting the fact that the majority of individuals with diabetes are overweight or obese. Until today the BMI is still used to classify overweight and obesity. Since reduced muscle mass is highly prevalent throughout the BMI range, the measurement of body composition is strongly recommended. Moreover, it is essential for monitoring the course of weight reduction, which is part of every effective anti-obesity treatment. Weight reduction can be achieved via different weight loss strategies, including lifestyle intervention (diet and exercise), pharmacotherapy, or bariatric surgery. However, not all of these strategies are suitable for all patients, and any further needs should be considered. Besides, attention should also be drawn to concomitant therapies. These therapies may promote additional weight gain and further trigger the deterioration of blood glucose control. Thus, therapeutic strategies are warranted, which can be easily used for the management of obese patients with type 2 diabetes to achieve their glycemic and weight loss goals.
\end{abstract}


Leitner et al.: Obesity and Type 2 Diabetes: Two Diseases with a Need for Combined Treatment Strategies - EASO Can Lead the Way

\section{Introduction}

Over the last century, obesity has emerged as leading global health concern through recent environmental and societal changes, favoring a positive energy balance and weight gain. The main factors are the consumption of high-calorie or high-fat foods, insufficient physical activity, and a shift towards a well-developed sedentary lifestyle [1]. Consequently, the prevalence of obesity nearly doubled worldwide since 1980. In 2014, more than $39 \%$ of the adults, who were 18 years or older, were overweight with $13 \%$ being obese. In addition, at least 41 million children under the age of 5 were overweight or obese according to the World Health Organization (WHO) [2]. Moreover, severe obesity (i.e., a BMI $>35 \mathrm{~kg} / \mathrm{m}^{2}$ ) is nowadays a rapidly growing segment of the global epidemic, which is especially marked by its negative effect on health as an increase in BMI implies an elevated mortality risk, like low BMI does [3-5]. Nonetheless, overweight and obesity are killing more people today than underweight [2].

Obesity is known to be the main risk factor for a number of non-communicable diseases like cardiovascular disease, type 2 diabetes, hypertension, coronary heart disease, or certain types of cancers. Besides, it also causes diverse psychological problems or various physical disabilities. In concordance with the WHO, overweight and obesity account for $44 \%$ of the diabetes cases, $23 \%$ of the ischemic heart disease patients, and around $7-41 \%$ of certain cancers $[4,5]$. Of these diseases, type 2 diabetes is most strongly associated with obesity, and the prevalence of obesity-related diabetes is expected to double to 300 million by 2025 [6]. This close relationship also led to the connotation 'diabesity', highlighting the fact that the majority of individuals with diabetes are overweight or obese $[7,8]$. Together, they increase the individuals' mortality risk 7-fold [9]. Consequently, obesity is today the largest global chronic health problem according to the WHO, and it is emerging as a more serious world health problem than malnutrition [5]. If this trend continues, $60 \%$ of the world's population will be overweight or obese by the year $2030[10,11]$.

In this review, the progressive nature of 'diabesity' will be discussed, focusing on antiobesity therapeutic strategies, including lifestyle management and bariatric surgery as well as pharmaceutically based strategies and their obstacles.

\section{Anthropometric Data}

The BMI is still used to classify overweight and obesity although the individual's body fat mass might be underestimated [12]. While a high proportion of body fat is almost regularly seen in people with a BMI of $>30 \mathrm{~kg} / \mathrm{m}^{2}$, it can be observed in almost one-third of people with normal weight, too [13]. Such inappropriate fat-muscle distribution is the result of a low muscle mass known as 'sarcopenia'. Quite a lot of these people can be identified through their elevated waist circumference, which should not exceed $80 \mathrm{~cm}$ for women and $94 \mathrm{~cm}$ for men in the Caucasian population [14]. Since there is a difference between ethnic groups in the association between BMI, waist, percentage of body fat and health risks, different BMI and waist cut-off points for various populations have been proposed [15]. Independent of the BMI threshold in various populations, a visceral fat distribution elevates the risk of atherosclerosis and mortality. Thus, the routine medical practice should include the standardized measurement of waist circumference as well as a proper method to measure the individual's body composition (dual energy X-ray absorptiometry (DEXA), bioelectrical impedance analysis (BIA), BOD-POD ${ }^{\circledR}$ ). Although these measurements have some drawbacks, they are essential for monitoring the course of weight reduction and the changes in the respective body compartments $[16,17]$. Moreover, the routine use of a simple, rapid, and 
inexpensive method to identify an early stage of sarcopenia should be discussed as the loss of muscle mass is nowadays quite common. In elderly this can be easily addressed by a questionnaire like SARC-F, which consists of 5 questions regarding strength, assistance in walking, rising from a chair, stair climbing, and falls. The global score of the SARC-F questionnaire ranges from 0 to 10 points, wherein each component is scored with $0-2$ points. A score $\geq 4$ points is reported to be predictive for sarcopenia and could be the trigger for a more detailed assessment of positively evaluated subjects [18]. The SARC-F questionnaire is so far one of the best available tools to screen for sarcopenia in routine medical practice, and its validity has already been proven in late-middle aged and elderly patients $[19,20]$. In order to get more information about muscle function, hand-grip tests are frequently performed and recommended [21].

\section{Weight Loss Strategies - Lifestyle Management}

The treatment of obesity is always intimately linked to the reduction of body weight. This can be achieved via different weight loss strategies, including lifestyle interventions (diet and exercise), pharmaceutical interventions, or bariatric surgery. Interestingly, gender differences in these strategies exist worldwide. While men prefer to exercise, women are more likely to join weight loss programs, take prescription diet pills, and follow special diets [22, 23]. In fact, it needs a combination of both preferences, resulting in weight loss by favoring a decrease in adiposity and an increase of lean mass in both sexes.

Exercise is the key component of every lifestyle intervention. Especially aerobic exercise is the best mode to reduce fat mass. Moreover, an increase in physical activity reduces intraabdominal fat, increases lean mass, decreases depression, and improves glucose tolerance, insulin sensitivity, and physical fitness. Thus, it is not surprising that all scientific guidelines recommend at least $150 \mathrm{~min} /$ week of moderate aerobic exercise combined with three weekly sessions of resistance training to increase muscle strength [1, 24-26]. However, the reality is that intensive lifestyle interventions are difficult to achieve and to maintain over a long period of time, even if the patients are included in an optimal clinical trial setting such as Look AHEAD (Action for Health in Diabetes) [27]. Although exercise is an important component of every effective weight loss strategy, several studies reported additive effects on weight loss when it is combined with an energy-restricted diet. This can be achieved either by a low-fat, lowcarbohydrate, or the Mediterranean-style diet [28-30]. The latter one is characterized by its beneficial metabolic effects as well as by its delayed need for an antihyperglycemic drug therapy in patients with newly diagnosed type 2 diabetes [31]. In any case, a low-fat diet should have an adequate carbohydrate source with complex carbohydrates instead of monoor disaccharides. However, it is not the diet type that determines the success of weight loss and cardiac risk factor reduction - it is the sustained diet adherence [32]. Thus, practical techniques to increase dietary adherence rates are urgently needed. One step towards this goal can be the use of a broad spectrum of different diet options to better match the patient's individual food preferences, lifestyle, and medical conditions. Additionally, the replacement of one or two meals per day by dietary supplements (low-calorie diets) might contribute to a nutritionally well-balanced diet and maintain weight loss [33]. Under certain conditions a very-low-calorie diet might support the weight loss objectives. However, this type of diet should only be limited to specific patients and for short periods of time. It is definitely not suitable for children, adolescents, or elderly people [1].

In the case of sarcopenia, appropriate intervention strategies slightly vary as the acquisition of muscle mass is essential. Consequently, exercise alone is not sufficient and has to be combined with a high-protein diet [34]. The timing of protein intake and the optimal amino 
Leitner et al:: Obesity and Type 2 Diabetes: Two Diseases with a Need for Combined

Treatment Strategies - EASO Can Lead the Way

acid composition are still controversially discussed. Besides the acquisition of muscle mass, the physical fitness as well as the overall physical activity of the patient is of great importance, especially at an advanced age $[35,36]$.

\section{Benefit of Weight Loss in Diabetes Prevention and Therapy}

Since the majority of people with type 2 diabetes are overweight or obese, weight reduction is seen as the key therapeutic goal in the prevention and the management of type 2 diabetes. For individuals, who have already progressed to pre-diabetes, the Finnish Diabetes Prevention Study showed that an intensive dietary and exercise program decreased the overall risk of diabetes by 58\% [37]. Similar results were obtained in the Diabetes Prevention Program, wherein moderate weight loss with lifestyle intervention in an obese population with impaired glucose tolerance could reduce the incidence of diabetes by $58 \%$, while metformin alone reduced it only by $31 \%$ [38]. Unfortunately, this study has not provided data regarding a combination of both strategies. Nevertheless, the improvement of insulin sensitivity and secretion can be directly correlated with a decreased risk of diabetes. In another study, each $1 \mathrm{~kg}$ weight loss in the first year of diabetes diagnosis was associated with 3-4 months of prolonged survival, and a weight loss of $10 \mathrm{~kg}$ was associated with the restoration of $35 \%$ in life expectancy [39].

For individuals with diabetes, Williamson et al. [40] could show that an intentional weight loss of $10 \mathrm{~kg}$ as seen in the American Cancer Society's Cancer Prevention Study I reduced the total mortality of people with diabetes about $25 \%$. Other clinical trials as the Look AHEAD study underlined the beneficial effects of weight loss in diabetes patients. This study demonstrated that a loss of $5-10 \%$ of body weight could improve the overall fitness, reduce HbA1c levels, improve cardiovascular disease risk factors, and decrease the use of antihyperglycemic, antihypertensive, and lipid-lowering medications after 1 year [41, 42]. Furthermore, weight loss supported the reduction of depression symptoms and the remission of obstructive sleep apnea or at least reduced its severity $[43,44]$. Interestingly, a weight loss of $>5 \%$ appears to be necessary for these beneficial effects. Since this requires intensive interventions, including energy restriction and regular physical activity, this amount of weight loss might not be a realistic primary treatment strategy for all overweight and obese patients. Nonetheless, these patients should be encouraged to reduce their energy intake, which may regardless of their weight loss - improve their glycemic control [45]. Besides, appropriate anti-obesity medications should be considered for those patients, who are still struggling with their weight management objectives.

\section{Implications for a Combined Anti-Obesity and Anti-Diabetes Treatment}

An effective treatment of obesity has the ability to improve body weight, body composition and glycemic control simultaneously. The necessity therefor has already been demonstrated by an observational study of Eeg-Olofsson et al. [46], wherein cardiovascular disease, stroke, and total mortality were correlated with weight gain during an antidiabetic drug therapy. So far such data do not prove a direct relationship of weight gain and morbidity as many factors might influence these results, but it may be used for hypothesis generation. At least it can be argued that the observation of weight gain is an indicator of less treatment success and potentially elevates the individuals' mortality risk. Appropriate intervention studies to evaluate weight gain during an antidiabetic drug therapy are not ethical and thus not performable. 
Given the strong association between the excess of weight and type 2 diabetes, the focus of a suitable antidiabetic treatment of obese patients should at least be the prevention of additional weight gain. Thus, glucose-lowering agents, which are weight neutral or support weight reduction, should be the first choice after the obligatory metformin therapy.

Currently, the options for an effective obesity pharmacotherapy vary worldwide. While several new drugs for weight management are available in the USA, only two of them - liraglutide (1.8 mg for type 2 diabetes and $3 \mathrm{mg}$ for obesity treatment) and the combination of naltrexone and bupropion - have been licensed in Europe in 2015 but have not been launched so far in most European countries. These pharmacotherapies have demonstrated to assist patients with type 2 diabetes in achieving their weight loss goals and improving their HbA1c levels [47]. An overview of all licensed anti-obesity drugs in the USA and in Europe has been published in OBESITY FACTS [48]. Evidence-based recommendations on using anti-obesity drugs in the diabetes management cannot be made so far, but it seems to be most likely that they could have a place in the future. Hence, there is a need for appropriate studies to further elucidate the effect of anti-obesity agents in diabetic populations.

\section{Bariatric (Metabolic) Surgery}

Bariatric surgery is an established and effective part of the weight loss management of morbidly obese patients. It is indicated in obese patients with a BMI $\geq 40 \mathrm{~kg} / \mathrm{m}^{2}$ or in individuals with a BMI $>35 \mathrm{~kg} / \mathrm{m}^{2}$ in the presence of type 2 diabetes or other major comorbidities [4]. In the latter case, bariatric surgery has proven to be highly beneficial in type 2 diabetes remissions and in the reduction of cardiovascular events as demonstrated in the Swedish Obese Subjects study [49]. Today these surgeries are also conducted in patients with lower BMI. To further address the potential value or risks, the results of controlled studies with an exact benefit-risk evaluation would be needed.

In contrast to obese patients without diabetes, those with diabetes have normally access to an interdisciplinary healthcare team, which enables them to fulfill all the required examinations during the pre-and postoperative phase. Although these patients are well embedded in the required medical care system, the perfect patients' selection remains difficult as longterm nutritional and micronutrient deficiencies requiring a lifelong vitamin/mineral supplementation can occur. Moreover, the rapid and massive weight loss of muscle and fat-free mass could also lead to malnutrition and osteoporosis. Thus, attention should be drawn to the body composition (muscle-fat distribution) and the bone health. Both should be examined at least 2 years after surgery [50].

\section{Comparison of Drug and Bariatric (Metabolic) Therapies}

Currently, bariatric therapies are more effective than drug therapies regarding weight reduction and metabolic processes - especially, when they are used to treat diabetes as demonstrated by the STAMPEDE (Surgical Treatment and Medications Potentially Eradicate Diabetes Efficiently) trial. The current 5-year follow-up analysis of this trial supports their prior findings that bariatric surgery is superior to intensive medical therapy in terms of glycemic control, weight reduction, decreasing medication use (antidiabetic, antihypertensive, and lipid-lowering agents) and improvement in quality of life. These beneficial effects were also observed among patients with mild obesity (BMI $27-34 \mathrm{~kg} / \mathrm{m}^{2}$ ) [51]. Since bariatric surgery is almost excluded in this patient population, the promising results of the STAMPEDE trial raise the question if bariatric surgery should also be an approved therapeutic approach 
Leitner et al.: Obesity and Type 2 Diabetes: Two Diseases with a Need for Combined Treatment Strategies - EASO Can Lead the Way

Table 1. Overview of different drug types and their observed trends in weight gain; single studies and the individual response may differ in the results

\begin{tabular}{ll}
\hline Drug class & Weight effect ${ }^{1}$ \\
\hline Antidiabetic treatments [59] & \\
Metformin & neutral \\
Alpha-glucosidase inhibitors & neutral \\
Glinides & neutral to + \\
Sulfonylureas & +) to ++ \\
Pioglitazone & neutral to ++ \\
DDP-IV inhibitors & neutral \\
SGLT-2 inhibitors & neutral to -- \\
GLP-agonists & neutral to --- \\
Insulin & + to +++ \\
\hline Antidepressant agents [60] & \\
Tricyclic antidepressants & \\
$\quad$ Amitriptyline, nortriptyline & $+/-$ \\
MAO inhibitors & \\
$\quad$ Phenelzine, tranylcypromine & +++ \\
$\quad$ Moclobemide & $0 /-$ \\
SSRI & $+/-$ \\
$\quad$ Citalopram, fluoxetine, paroxetine, sertraline & \\
SNRI & \\
$\quad$ Duloxetine, venlafaxine, milnacipran & $0 /-$ \\
Others & \\
Bupropion & $0 /-$ \\
Mirtazapine & ++ \\
Lithium & $+++[61]$ \\
\hline
\end{tabular}

\section{Antipsychotic agents [60]}

Clozapine

Olanzapine

Risperidone

Quetiapine

Aripiprazole

Ziprasidone

Haloperidol

Pherphenazine

+++
+++
++
++
$0 /+$
$0 /+$
$+++[62]$
$+/-[63]$

Antiepileptics

Valproic acid

Carbamazepine

++ to $+++[53,64-66]$

Gabapentin

+ to $++(+)[65-68]$

+ to $+++[69,70]$

Steroid hormones

Oral corticosteroids (prednisone)

Hormone therapy-contraception (DMPA)

+ to $++(+)[71,72]$

+ to $++[73]$

Miscellaneous agents

Beta-adrenergic blockers (propanolol, metoprolol, atenolol)

+ to $++[52]$

1+++ Significant; ++ moderate; + slight weight gain; 0/+ slightly increasing effect; +/- inconsistent data; 0/- minimal to no weight reduction; -- moderate; --- significantly weight loss. 
for patients with a BMI less than $35 \mathrm{~kg} / \mathrm{m}^{2}$. However, further long-time cohort studies are needed.

Unfortunately, anti-obesity agents have not been evaluated so far in patients who received bariatric surgery. Nonetheless, mono- or combination therapies using these weight loss drugs could have the potential to improve the long-term success in weight loss and maintenance.

\section{Concomitant Therapies}

Suitable anti-obesity treatments should consider concomitant therapies, which are not associated with weight gain. Unfortunately, this turned out to be a complex therapeutic challenge, as a number of pharmaceuticals tend to increase the patients' body weight. For many of them, the exact mechanism that causes weight gain is so far not known. Some affect the metabolism and lead to an increased appetite (antidepressants, antipsychotics, anti-epileptics, diabetes medications), cause fluid retention (diabetes medication), or slowly induce weight gain over a period of time due to fatigue and lower activity (beta blocker) [52-58]. Among them, antipsychotics represent the most important ones. However, the net weight gain varies from person to person and from drug to drug. Consequently, it can vary between a few kilograms in 1 year, to 10 or even more kilograms in just a few months. Since these medications are quite often used during chronic conditions, they significantly contribute to the individuals' weight gain over time (for an overview see table 1). Thus, attention has to be drawn to distinguish between weight gain, which is related to a specific treatment, and weight gain due to other factors like an inappropriate diet or lack of exercise. Although this is quite difficult, it will be the only option to elucidate a suitable therapy for each patient, especially when weight loss should be promoted.

Furthermore, the potential of weight gain is also discussed for several other therapeutic drugs, e.g. antihistamines like loratadine, fexofenadine, cycloheptadine, diphenhydramine, and doxepine. Although a number of drugs tend to increase body weight like psychotropic drugs, there are some, which have the potential to be either weight-neutral (e.g. the antiepileptic drug lamotrigine) or may induce weight loss (e.g. the anti-epileptic drugs topiramate and zonisamide) [74]. Consequently, these drugs should be considered as alternatives, especially when weight loss is an objective.

\section{Conclusion}

As obesity is an emerging epidemic of modern societies, the co-incidence with diabetes is also emerging. The resulting 'diabesity' raises the question whether weight management and diabetes should be targeted with combined treatment strategies. Data from registries show a tendency to decreased treatment success in diabetes whenever weight gain is observed. Additionally, concomitant therapies may increase body weight further with a deterioration of blood glucose control. Taken together, these observations should be the basis for a combined view of anti-obesity and antidiabetic treatment strategies. Studies based on that are warranted.

\section{Disclosure Statement}

DRL, KS and EW reported no conflict of interest. GF has participated in a Novo Nordisk Obesity Scientific Communication Global Advisory Board Meeting. VY is on the national obesity advisory board of Novo Nordisk. DM has served as advisor and speaker for Novo Nordisk and Astra Zeneca. HT has served as advisor and speaker for Novo Nordisk, Vivus and Orexigen. 
Leitner et al.: Obesity and Type 2 Diabetes: Two Diseases with a Need for Combined

Treatment Strategies - EASO Can Lead the Way

\section{References}

1 Yumuk V, Tsigos C, Fried M, Schindler K, Busetto L, Micic D, Toplak H, Obesity Management Task Force of the European Association for the Study of Obesity: European guidelines for obesity management in adults. Obes Facts 2015;8:402-424.

2 WHO: Obesity and Overweight. Fact sheet No.311.2016. www.who.int/mediacentre/factsheets/fs311/en/(last accessed September 28, 2017)

3 Prospective Studies Collaboration, Whitlock G, Lewington S, Sherliker P, Clarke R, Emberson J, Halsey J, Qizilbash N, Collins R, Peto R: Body-mass index and cause-specific mortality in 900000 adults: collaborative analyses of 57 prospective studies. Lancet 2009;373:1083-1096.

4 Fried M, Yumuk V, Oppert JM, Scopinaro N, Torres AJ, Weiner R, Yashkov Y, Frühbeck G; European Association for the Study of Obesity, International Federation for the Surgery of Obesity - European Chapter: Interdisciplinary European guidelines on metabolic and bariatric surgery. Obes Facts 2013;6:449-468.

5 Frühbeck G, Toplak H, Woodward E, Yumuk V, Maislos M, Oppert JM; Executive Committee of the European Association for the Study of Obesity: Obesity: the gateway to ill health - an EASO position statement on a rising public health, clinical and scientific challenge in Europe. Obes Facts 2013;6:117-120.

6 Dyson PA: The therapeutics of lifestyle management on obesity. Diabetes Obes Metab 2010;12:941-946.

7 International Diabetes Federation: Diabetes Atlas, 2nd ed. Brussels, International Diabetes Federation, 2003. www.diabetesatlas.org/component/attachments/?task=download\&id=73 (last accessed September 28, 2017).

8 Hossain P, Kawar B, El Nahas M: Obesity and diabetes in the developing world - a growing challenge. N Engl J Med 2007;356:213-215.

9 Oldridge NB, Stump TE, Nothwehr FK, Clark DO: Prevalence and outcomes of comorbid metabolic and cardiovascular conditions in middle- and older-age adults. J Clin Epidemiol 2001;54:928-934.

10 Kelly T, Yang W, Chen CS, Reynolds K, He J: Global burden of obesity in 2005 and projections to 2030. Int J Obes (Lond) 2008;32:1431-1437.

11 Finucane MM, Stevens GA, Cowan MJ, Danaei G, Lin JK, Paciorek CJ, Singh GM, Gutierrez HR, Lu Y, Bahalim AN, Farzadfar F, Riley LM, Ezzati M, Global Burden of Metabolic Risk Factors of Chronic Diseases Collaborating Group: National, regional, and global trends in body-mass index since 1980:systematic analysis of health examination surveys and epidemiological studies with 960 country-years and 9.1 million participants. Lancet 2011;377:557-567.

12 Blundell JE, Dulloo AG, Salvador J, Frühbeck G; EASO SAB Working Group on BMI: Beyond BMI - phenotyping the obesities. Obes Facts 2014;7:322-328.

13 Gomez-Ambrosi J, Silva C, Galofre JC, Escalada J, Santos S, Millan D, Vila N, Ibanez P, Gil MJ, Valenti V, Rotellar F, Ramirez B, Salvador J, Frühbeck G: Body mass index classification misses subjects with increased cardiometabolic risk factors related to elevated adiposity. Int J Obes (Lond) 2012;36:286-294.

14 Cameron AJ, Sicree RA, Zimmet PZ, Alberti KG, Tonkin AM, Balkau B, Tuomilehto J, Chitson P, Shaw JE: Cutpoints for waist circumference in Europids and South Asians. Obesity (Silver Spring) 2010;18:2039-2046.

15 WHO Expert Consultation: Appropriate body-mass index for Asian populations and its implications for policy and intervention strategies. Lancet 2004;363:157-163.

16 Tsigos C, Hainer V, Basdevant A, Finer N, Fried M, Mathus-Vliegen E, Micic D, Maislos M, Roman G, Schutz Y, Toplak H, Zahorska-Markiewicz B; Obesity Management Task Force of the European Association for the Study of Obesity: Management of obesity in adults: European clinical practice guidelines. Obes Facts 2008;1:106-116.

17 Yumuk V, Frühbeck G, Oppert JM, Woodward E, Toplak H: An EASO position statement on multidisciplinary obesity management in adults. Obes Facts 2014;7:96-101.

18 Beaudart C, McCloskey E, Bruyere O, Cesari M, Rolland Y, Rizzoli R, Araujo de Carvalho I, Amuthavalli Thiyagarajan J, Bautmans I, Bertiere MC, Brandi ML, Al-Daghri NM, Burlet N, Cavalier E, Cerreta F, Cherubini A, Fielding R, Gielen E, Landi F, Petermans J, Reginster JY, Visser M, Kanis J, Cooper C: Sarcopenia in daily practice: assessment and management. BMC Geriatr 2016;16:170.

19 Morley JE, Anker SD, von Haehling S: Prevalence, incidence, and clinical impact of sarcopenia: facts, numbers, and epidemiology-update 2014. J Cachexia Sarcopenia Muscle 2014;5:253-259.

20 Malmstrom TK, Miller DK, Simonsick EM, Ferrucci L, Morley JE: SARC-F: a symptom score to predict persons with sarcopenia at risk for poor functional outcomes. J Cachexia Sarcopenia Muscle 2016;7:28-36.

21 Otto M, Kautt S, Kremer M, Kienle P, Post S, Hasenberg T: Handgrip strength as a predictor for post bariatric body composition. Obes Surg 2014;24:2082-2088.

22 Grebitus C, Hartmann M, Reynolds N: Global obesity study on drivers for weight reduction strategies. Obes Facts 2015;8:77-86.

23 Tsai SA, Lv N, Xiao L, Ma J: Gender differences in weight-related attitudes and behaviors among overweight and obese adults in the United States. Am J Mens Health 2016;10:389-398.

24 Poirier P, Despres JP: Exercise in weight management of obesity. Cardiol Clin 2001;19:459-470.

25 Willis LH, Slentz CA, Bateman LA, Shields AT, Piner LW, Bales CW, Houmard JA, Kraus WE: Effects of aerobic and/or resistance training on body mass and fat mass in overweight or obese adults. J Appl Physiol 2012;113: 1831-1837.

26 Geliebter A, Ochner CN, Dambkowski CL, Hashim SA: Obesity-related hormones and metabolic risk factors: a randomized trial of diet plus either strength or aerobic training versus diet alone in overweight participants. J Diabetes Obes 2014;1:1-7. 
Leitner et al.: Obesity and Type 2 Diabetes: Two Diseases with a Need for Combined

Treatment Strategies - EASO Can Lead the Way

27 Look ARG: Eight-year weight losses with an intensive lifestyle intervention: the Look AHEAD study. Obesity (Silver Spring) 2014;22:5-13.

28 Shai I, Schwarzfuchs D, Henkin Y, Shahar DR, Witkow S, Greenberg I, Golan R, Fraser D, Bolotin A, Vardi H, Tangi-Rozental O, Zuk-Ramot R, Sarusi B, Brickner D, Schwartz Z, Sheiner E, Marko R, Katorza E, Thiery J, Fiedler GM, Bluher M, Stumvoll M, Stampfer MJ, Dietary Intervention Randomized Controlled Trial Group: Weight loss with a low-carbohydrate, Mediterranean, or low-fat diet. N Engl J Med 2008;359:229-241.

29 Larsen RN, Mann NJ, Maclean E, Shaw JE: The effect of high-protein, low-carbohydrate diets in the treatment of type 2 diabetes: a 12 month randomised controlled trial. Diabetologia 2011;54:731-740.

30 Krebs JD, Elley CR, Parry-Strong A, Lunt H, Drury PL, Bell DA, Robinson E, Moyes SA, Mann JI: The Diabetes Excess Weight Loss (DEWL) Trial: a randomised controlled trial of high-protein versus high-carbohydrate diets over 2 years in type 2 diabetes. Diabetologia 2012;55:905-914.

31 Esposito K, Maiorino MI, Ciotola M, Di Palo C, Scognamiglio P, Gicchino M, Petrizzo M, Saccomanno F, Beneduce F, Ceriello A, Giugliano D: Effects of a Mediterranean-style diet on the need for antihyperglycemic drug therapy in patients with newly diagnosed type 2 diabetes: a randomized trial. Ann Intern Med 2009;151:306-314.

32 Dansinger ML, Gleason JA, Griffith JL, Selker HP, Schaefer EJ: Comparison of the Atkins, Ornish, Weight Watchers, and Zone diets for weight loss and heart disease risk reduction: a randomized trial. JAMA 2005;293:43-53.

33 Wadden TA, West DS, Neiberg RH, Wing RR, Ryan DH, Johnson KC, Foreyt JP, Hill JO, Trence DL, Vitolins MZ, Look ARG: One-year weight losses in the Look AHEAD study: factors associated with success. Obesity (Silver Spring) 2009;17:713-722.

34 Wycherley TP, Buckley JD, Noakes M, Clifton PM, Brinkworth GD: Long-term effects of a very low-carbohydrate weight loss diet on exercise capacity and tolerance in overweight and obese adults. J Am Coll Nutr 2014; 33:267-273.

35 Cawthon PM, Fox KM, Gandra SR, Delmonico MJ, Chiou CF, Anthony MS, Sewall A, Goodpaster B, Satterfield S, Cummings SR, Harris TB, Health A, Body Composition S: Do muscle mass, muscle density, strength, and physical function similarly influence risk of hospitalization in older adults? Am Geriatr Soc 2009;57:14111419.

36 Hainer V, Toplak H, Stich V: Fat or fit: what is more important? Diabetes Care 2009;32(suppl 2):S392-397.

37 Lindström J, Louheranta A, Mannelin M, Rastas M, Salminen V, Eriksson J, Uusitupa M, Tuomilehto J, Finnish Diabetes Prevention Study Group: The Finnish Diabetes Prevention Study (DPS): lifestyle intervention and 3-year results on diet and physical activity. Diabetes Care 2003;26:3230-3236.

38 Knowler WC, Barrett-Connor E, Fowler SE, Hamman RF, Lachin JM, Walker EA, Nathan DM, Diabetes Prevention Program Research G: Reduction in the incidence of type 2 diabetes with lifestyle intervention or metformin. N Engl J Med 2002;346:393-403.

39 Lean ME, Powrie JK, Anderson AS, Garthwaite PH: Obesity, weight loss and prognosis in type 2 diabetes. Diabet Med 1990; 7:228-233.

40 Williamson DF, Thompson TJ, Thun M, Flanders D, Pamuk E, Byers T: Intentional weight loss and mortality among overweight individuals with diabetes. Diabetes Care 2000;23:1499-1504.

41 Wing RR, Lang W, Wadden TA, Safford M, Knowler WC, Bertoni AG, Hill JO, Brancati FL, Peters A, Wagenknecht L, Look ARG: Benefits of modest weight loss in improving cardiovascular risk factors in overweight and obese individuals with type 2 diabetes. Diabetes Care 2011;34:1481-1486.

42 Look ARG, Wing RR: Long-term effects of a lifestyle intervention on weight and cardiovascular risk factors in individuals with type 2 diabetes mellitus: four-year results of the Look AHEAD trial. Arch Intern Med 2010; 170:1566-1575.

43 Foster GD, Borradaile KE, Sanders MH, Millman R, Zammit G, Newman AB, Wadden TA, Kelley D, Wing RR, Pi-Sunyer FX, Reboussin D, Kuna ST; Sleep AHEAD Research Group of Look AHEAD Research Group: A randomized study on the effect of weight loss on obstructive sleep apnea among obese patients with type 2 diabetes: the Sleep AHEAD study. Arch Intern Med 2009;169:1619-1626.

44 Rubin RR, Wadden TA, Bahnson JL, Blackburn GL, Brancati FL, Bray GA, Coday M, Crow SJ, Curtis JM, Dutton G, Egan C, Evans M, Ewing L, Faulconbridge L, Foreyt J, Gaussoin SA, Gregg EW, Hazuda HP, Hill JO, Horton ES, Hubbard VS, Jakicic JM, Jeffery RW, Johnson KC, Kahn SE, Knowler WC, Lang W, Lewis CE, Montez MG, Murillo A, Nathan DM, Patricio J, Peters A, Pi-Sunyer X, Pownall H, Rejeski WJ, Rosenthal RH, Ruelas V, Toledo K, Van Dorsten B, Vitolins M, Williamson D, Wing RR, Yanovski SZ, Zhang P, Look ARG: Impact of intensive lifestyle intervention on depression and health-related quality of life in type 2 diabetes: the Look AHEAD Trial. Diabetes Care 2014;37:1544-1553.

45 Franz MJ: The role of weight loss in the management of type 2 diabetes. US Endocrinol 2016;12:14-15.

46 Eeg-Olofsson K, Cederholm J, Nilsson PM, Zethelius B, Nunez L, Gudbjörnsdottir S, Eliasson B: Risk of cardiovascular disease and mortality in overweight and obese patients with type 2 diabetes: an observational study in 13,087 patients. Diabetologia 2009;52:65-73.

47 Van Gaal L, Scheen A: Weight management in type 2 diabetes: current and emerging approaches to treatment. Diabetes Care 2015;38:1161-1172.

48 Toplak H, Woodward E, Yumuk V, Oppert JM, Halford JC, Frühbeck G: 2014 EASO position statement on the use of anti-obesity drugs. Obes Facts 2015;8:166-174.

49 Sjöholm K, Pajunen P, Jacobson P, Karason K, Sjöström CD, Torgerson J, Carlsson LM, Sjöström L, Peltonen M: Incidence and remission of type 2 diabetes in relation to degree of obesity at baseline and 2 year weight change: the Swedish Obese Subjects (SOS) study. Diabetologia 2015;58:1448-1453. 
Leitner et al:: Obesity and Type 2 Diabetes: Two Diseases with a Need for Combined

Treatment Strategies - EASO Can Lead the Way

50 Thibault R, Huber O, Azagury DE, Pichard C: Twelve key nutritional issues in bariatric surgery. Clin Nutr 2016; 35:12-17.

51 Schauer PR, Bhatt DL, Kirwan JP, Wolski K, Aminian A, Brethauer SA, Navaneethan SD, Singh RP, Pothier CE, Nissen SE, Kashyap SR; STAMPEDE Investigators: Bariatric surgery versus intensive medical therapy for diabetes - 5-year outcomes. N Engl J Med 2017;376:641-651.

52 Sharma AM, Pischon T, Hardt S, Kunz I, Luft FC: Hypothesis: beta-adrenergic receptor blockers and weight gain: a systematic analysis. Hypertension 2001;37:250-254.

53 Hamed SA: Antiepileptic drugs influences on body weight in people with epilepsy. Expert Rev Clin Pharmacol 2015;8:103-114.

54 Garland EJ, Remick RA, Zis AP: Weight gain with antidepressants and lithium. J Clin Psychopharmacol 1988; 8:323-330.

55 Mitri J, Hamdy 0: Diabetes medications and body weight. Expert Opin Drug Saf 2009;8:573-584.

56 Yang T, Soodvilai S: Renal and vascular mechanisms of thiazolidinedione-induced fluid retention. PPAR Res 2008;2008:943614.

57 Jensen-Otsu E, Austin GL: Antidepressant use is associated with increased energy intake and similar levels of physical activity. Nutrients 2015;7:9662-9671.

58 Baptista T, Zarate J, Joober R, Colasante C, Beaulieu S, Paez X, Hernandez L: Drug induced weight gain, an impediment to successful pharmacotherapy: focus on antipsychotics. Curr Drug Targets 2004;5:279-299.

59 Toplak H, Hoppichler F, Wascher TC, Schindler K, Ludvik B: Obesity and type 2 diabetes (in German). Wien Klin Wochenschr 2016;128(suppl 2):S196-200.

60 Abrahamian H, Kautzky-Willer A, Riessland-Seifert A, Fasching P, Ebenbichler C, Hofmann P, Toplak H: Mental disorders and diabetes mellitus (in German). Wien Klin Wochenschr 2016;128(suppl 2):S170-178.

61 Gitlin M: Lithium side effects and toxicity: prevalence and management strategies. Int J Bipolar Disord 2016; $4: 27$.

62 Perez-Iglesias R, Crespo-Facorro B, Martinez-Garcia O, Ramirez-Bonilla ML, Alvarez-Jimenez M, Pelayo-Teran JM, Garcia-Unzueta MT, Amado JA, Vazquez-Barquero JL: Weight gain induced by haloperidol, risperidone and olanzapine after 1 year: findings of a randomized clinical trial in a drug-naive population. Schizophr Res 2008; 99:13-22.

63 Hermes E, Nasrallah H, Davis V, Meyer J, McEvoy J, Goff D, Davis S, Stroup TS, Swartz M, Lieberman J, Rosenheck R: The association between weight change and symptom reduction in the CATIE schizophrenia trial. Schizophr Res 2011;128:166-170.

64 El-Khatib F, Rauchenzauner M, Lechleitner M, Hoppichler F, Naser A, Waldmann M, Trinka E, Unterberger I, Bauer G, Luef GJ: Valproate, weight gain and carbohydrate craving: a gender study. Seizure 2007;16:226-232.

65 Corman CL, Leung NM, Guberman AH: Weight gain in epileptic patients during treatment with valproic acid: a retrospective study. Can J Neurol Sci 1997;24:240-244.

66 Mattson RH, Cramer JA, Collins JF: A comparison of valproate with carbamazepine for the treatment of complex partial seizures and secondarily generalized tonic-clonic seizures in adults. The Department of Veterans Affairs Epilepsy Cooperative Study No. 264 Group. N Engl J Med 1992;327:765-771.

67 Gaspari CN, Guerreiro CA: Modification in body weight associated with antiepileptic drugs. Arq Neuropsiquiatr 2010;68:277-281.

68 Lampl Y, Eshel Y, Rapaport A, Sarova-Pinhas I: Weight gain, increased appetite, and excessive food intake induced by carbamazepine. Clin Neuropharmacol 1991;14:251-255.

69 DeToledo JC, Toledo C, DeCerce J, Ramsay RE: Changes in body weight with chronic, high-dose gabapentin therapy. Ther Drug Monit 1997;19:394-396.

70 Baulac M, Cavalcanti D, Semah F, Arzimanoglou A, Portal JJ: Gabapentin add-on therapy with adaptable dosages in 610 patients with partial epilepsy: an open, observational study. The French Gabapentin Collaborative Group. Seizure 1998;7:55-62.

71 Berthon BS, MacDonald-Wicks LK, Wood LG: A systematic review of the effect of oral glucocorticoids on energy intake, appetite, and body weight in humans. Nutr Res 2014;34:179-190.

72 Manaboriboon B, Silverman ED, Homsanit M, Chui H, Kaufman M: Weight change associated with corticosteroid therapy in adolescents with systemic lupus erythematosus. Lupus 2013;22:164-170.

73 Berenson $\mathrm{AB}$, Rahman M: Changes in weight, total fat, percent body fat, and central-to-peripheral fat ratio associated with injectable and oral contraceptive use. Am J Obstet Gynecol 2009;200:329 e321-328.

74 Ben-Menachem E: Weight issues for people with epilepsy - a review. Epilepsia 2007;48(suppl 9):42-45. 